\title{
Effect of Educational Program on Nurses Performance about Colostomy Care
}

\author{
Hanaa Abd El-latief shahat Ali, Jehan Sayyed Ali, Sahar Hamza Taha.
}

(1) B.Sc. in Nursing- Faculty of Nursing_Minia University,

(2) Professor of Medical Surgical Nursing -Faculty of Nursing_Minia University,

(3) Lecturer of Medical Surgical Nursing- Faculty of Nursing__Minia University

\begin{abstract}
Background: Colostomy is a stoma which is formed after removing the large bowel or colon and is opening in the abdominal wall that's made during surgery. The care of patients with colostomy is a complex, challenging and lengthy process. The nurse can play a clinically relevant role in the care of patient undergoing ostomy surgery pre and postoperative education. Aim of the study: to evaluate effect of educational program on nurses' performance about colostomy care. Subjects \&Methods: Research design: a quasi-experimental design was utilized to fulfill the purpose of this study. Sample: Randomized sample conducted on 40 nurses caring for patient with colostomy .Setting: two setting: $\mathbf{1}^{\text {st }}$ setting at Oncology Center $\& 2^{\text {nd }}$ setting at Minia University Hospital. Tools: Two tools were used for data collection: First Tool: included two parts: part I: socio demographic data sheet for the nurses, part II: structured knowledge questionnaire second tool: observational checklist about colostomy care. Results: Reveled that the mean age of study sample was $32.95 \pm 3.65$, the majority $(85 \%)$ of the studied sample had low knowledge before educational program implementation while, after 3 months of program implementation the majority $(85 \%)$ had a good knowledge about colostomy care. Also all of study sample had weak performance before educational program implementation while, in post immediately of program implementation more than half of studied sample $(52.5 \%)$ had accepted performance and after 3 months the majority of them had a good performance about colostomy care. Also, there was a highly statistically significant difference in nurses' knowledge and practice pre \& post immediately and after 3 months educational program regarding colostomy care. Conclusion: The study concluded that, there was a positive effect of the educational program in improving nurses' knowledge and practices regarding colostomy care. Recommendations: Greater attention and closely observation from hospital on nurses' performance during care for patient with colostomy and replication of the study should be done on a large sample.

Key word: colostomy, nurses 'performance, educational program.
\end{abstract}

\section{Introduction}

Colorectal cancer (CRC) has a major international health concern because of its high incidence and mortality rates (Favoriti, et al., 2016). The $\mathrm{CRC}$, which comprises approximately 1 million and 400 new cases and about 700 deaths, is the third most prevalent type of malignancy in the United Nations Association and the 4th largest global cause of cancer mortality worldwide (Arnold, et al., 2016).

Over the past few years, the prevalence of CRC has increased enormously; in particular, the number of newly diagnosed CRC cases has increased from 700 to 83000 in 1990 to 1 million and 311000 in 2012 (Ferlay, et al., 2015 \&Rafiemanesh, et al., 2016). The colostomy is a stoma that is formed after removing the large bowel or colon and is an opening in the abdominal wall that's made during surgery (Laughlin \& Rullier, 2018).

The most secure type of treatment can include acute diverticulitis, rectal cancer, trauma, or bowel-inflammatory conditions (Huang, et al., 2020). Physical and psychological issues including anxiety, shame, depression, and a negative physical image affect patients with a stoma (Betty Lebona, et al., 2016).

Nurses can play a major part in the understanding and have an important role in adjustment to the colostomy patients and their families. This position is only effective if the nurses have expertise and skills help (Chindaprasirt, et al., 2017).

Initial evaluation and education help for patients in the colostomy surgery, before and after surgery, however, Patient care and education quality are influenced by the expertise and capacity of nurses. Since patient care is one of the tasks of nurses, they need enough expertise to care for patients (Duruk \& Uçar, 2018).

Therefore, the understanding of nursing skills and expertise influences patient education and healthcare satisfaction. Nurses should be qualified before hospital discharge to determine the physical, psychological, and cultural needs of the patient (Nazike Duruk, 2017).

\section{Significance of the Study}

United Ostomy Association (UOA) 2015 stated that over 750,000 Americans currently have an ostomy. However, about $36 \%$ of the surgeries performed are colostomies. While, in Hong Kong (2017), there are approximately 15,000 patients with a stoma. Furthermore, in the Netherlands in 2017, there are about 32,000persons with a permanent stoma. Other report estimates that 650,000 people in Egypt currently have a stoma and about 3000 new surgeries are performed each year with a colostomy (Sheikh et al., 2013).

Evidence-based practice (EBP) has demonstrated that preoperative ostomy education is more effective than postoperative. Instituting a coordinated EBP approach preoperatively to ostomy care resulted in $75 \%$ of participants achieving ostomy independence in 5 days or less (Bryan \& Dukes, 2017). Preoperative ostomy nurse education programs are associated with a greater probability for improvement in the ostomy patient outcomes (Subih \& Neil, 2016).

\section{Aim of the Study}

The current study aimed to assess the effect of educational program on nurse's performance about colostomy care. 


\section{Research hypothesis:}

(1) There will be a significant difference between the pre-test and post-test of knowledge level regarding colostomy care among study sample nurses.

(2) There will be a significant difference between the pre-test and post-test of practice level regarding colostomy care among study sample nurses.

(3) There will be a positive relationship between selected socio-demographic variables and nurses performance.

\section{Research Design}

A Quazi- experimental research design was utilized to fulfill the aim of this study.

\section{Setting}

The current study was carried out at two settings: $\mathbf{1}^{\text {st }}$ setting oncology center (Surgical department, inpatient chemotherapy department), $\mathbf{2}^{\text {nd }}$ setting Minia University Hospital (General surgical department).

\section{Sample}

The sample was selected by randomization method (40) of all nurses who were working in the selected settings that mentioned before and were participate in the study would be included.

\section{Inclusion Criteria for the nurses:-}

All nurses are on duties.

\section{Exclusion Criteria for the nurses:}

Nurses who aren't will to participate in this study.

\section{Study Duration:}

The total data collection was collected over a period of six months starting from July 2019 to December 2019

\section{Data Collection Tools:}

Tools of data collection were developed by the researcher after extensive review of literature and similar studies conducted elsewhere. After that the developed questionnaires are revised by 5 panels of medical surgical nursing staff, a structured knowledge questionnaire was developed.

\section{Data collection: The data was collected by using two tools:} The First Tool:

Part I: Socio demographic data sheet for nurses including (age - gender - working department - educational status-occupation-years of experiences, etc.

Part II : Structured knowledge questionnaire to assess nurses knowledge about colostomy care, it was modified by the researcher after extensive literature review and it includes 20 questions about colostomy care such as meaning of colostomy, indication, types, normal appearance of the stoma, types of pouches ......etc.

\section{Scoring System:}

- Each correct answer was given a score of one and incorrect answer a score of zero, it was assigned for each answer representation (correct, incorrect) respectively.

- Total score for knowledge questionnaire about colostomy care classified as (low knowledge $<60 \%$
(<12 score), moderate knowledge 60\% - 75\% (12-15 score), high knowledge $\geq 75 \%$ (15- score or above) (Nabeel, et al., 2013).

\section{Second Tool: "Observational Checklist Sheet about Colostomy Care":}

- This sheet was filled by the researcher, it was adopted from (Potter ,et al., 2016), it consists of $4^{\text {th }}$ domains for evaluating nursing practice about colostomy care :

○ $\mathbf{1}^{\text {st }}$ domain assessment of the stoma and peristomal skin including (7) steps.

○ $\mathbf{2}^{\text {nd }}$ domain Applying new ostomy appliance including (25) step.

- $3^{\text {rd }}$ domain irrigation of the stoma including (27) step.

$\circ 4^{\text {th }}$ domain emptying the pouch including (8) steps.

\section{Scoring System:}

The score for each domain rank from $(0-1-2)$, not done was given a score $(0)$, done in-correctly was given a score (1), done correctly given a score (2) the score for each item were summed to create a total score 134 items.

Total observational checklist about colostomy care $(\geq$ $60 \%$ ) was considered satisfactory, $(<60 \%)$ was considered unsatisfactory.

Total scores were classified as (weak performance $<$ $60 \%$, acceptance performance $60 \%-75 \%$, good performance knowledge $\geq 75 \%$.

Tools validity

The study tools were developed after reviewing the related literature .To determine content and face validity, these tools were tested by a Jure committee that consists of five medical-surgical nursing experts. Recommendations were followed, the questions that were not appropriate were taken out and some questions needed clarification and modifications were done.

\section{Tools reliability}

Tools were tested for content reliability using Alpha Cronbach'stest.it was (0.96) for the first tool, (0.86) for the second tool.

\section{Pilot study}

A pilot study was conducted on (4 nurses) $10 \%$ of the total sample to test feasibility, objectivity, and applicability of the data collection tool .To estimate the needed time to fill the data collection. Based on the results of the pilot study, no refinement/modifications were done for data collection instruments; nurses who shared in the pilot study were included in the actual study sample.

\section{Ethical Consideration}

An official permission to carry out the study was obtained from the ethical committee of the faculty of nursing, dean of nursing faculty, Oncology Center director and Minia University Hospital director.

Subject's participation in this study was voluntary, they were informed about the importance, aim, nature, and purpose of the study, and they had the right to withdraw from the study at any time without any rationale. Oral and written consents were obtained from subjects; they were informed that 
the obtained data will not be included at any further researches without a second consent. Confidentiality and anonymity of each subject were ensured through coding of all data and protecting the obtained data.

\section{Procedure}

The current study was achieved through three phases, Assessment phase (pre- test), implementation phase (conducting education program) post-test immediately, and follow up phase.

\section{1-Assessment phase :-(pre-test)}

Once official permission were granted, the assessment phase (pre-test) collected through(six weeks) to test studied sample actual level of knowledge and practice regarding colostomy care.

The researcher collected the sample through three days per week (In morning \&evening shift). The study was carried out in the period from july2019through December.

- During assessment phase the researcher held the first meeting with nurses to introduce herself and giving an explanation about the nature and purpose of the study .they were informed that about participation in this study is voluntary and they had the right to withdraw at any time, oral approval of nurses to share in the study was achieved.

- After obtaining the acceptance from nurses to participate in the current study, the researcher provided an over view and clarification about the assessment questionnaire then the self- administered questionnaire was distributed to each nurse to assess data related to socio-demographic status(Appendix A) ,the questionnaire took about 15 minute to be completed.

- The total sample (40) was divided in to small group (4 group) each group consists of (10) nurses, each group received (3) session.

- The time of each session was taken (35 to 45) minutes.

- First session of assessment phase (pre-test) the researcher assesses knowledge of nurses about colostomy care by using $1^{\text {st }}$ tool (Appendix A).

- $\quad$ Second \&Third session of assessment phase (pre-test) the researcher assess practice of nurses about colostomy care by using $2^{\text {nd }}$ tool (Appendix B).

\section{2- Implementation phase:( post-test immediately)}

- During implementation of education program, the nurse in the study sample received the knowledge about colostomy care and the researcher applies the following procedures to the patient in front of nurses: how to assess stoma and peristomal skin, changing the ostomy appliance, colostomy irrigation and pouch emptying.

- Then allow nurses to asking questions, discussion and reach high level of understanding.

- This phase also was taken three sessions for each group (10 nurses), each session took about (30-45 minutes).

- During first session the researcher explained knowledge and demonstrated steps of colostomy care that mention before, applied the procedure of pouch emptying, assessment of stoma and peristomal skin care ,according to checklist in front of study sample group.

- Second session: the researcher applied the procedure of changing an ostomy appliance and colostomy irrigation, according to checklist in front of study sample group.

- Third session: post-test immediately was done for each group by using $1^{\text {st }}$ tool $\& 2^{\text {nd }}$ tool (Appendix A\& Appendix B).

\section{3-Evaluation phase (follow up)}

Three time of evaluation were done for each nurse:

(1) First time of evaluation (pretest) done before implementation of the knowledge questionnaire and observational checklist about colostomy care.

(2) Second time of evaluation (immediate posttest ) done immediately after explanation of knowledge questionnaire about colostomy care $\&$ application of procedures to patient in front of nurses about (assessment of stoma and peristomal skin care, changing an ostomy appliance, colostomy irrigation and emptying the pouch).

(3) Third time of evaluation(posttest) done after 3 months of assessing nurses about knowledge \& practice related to colostomy care of patient.

- The entire study sample received brochure as a guide (Appendix E) (in Arabic) it was developed by the researcher and revised by 5 panels of medical surgical nursing staff, it was included (knowledge\& practice related to colostomy care.

\section{Statistical analysis of data}

The collected data were organized, tabulated, categorized analyzed, and data entry was performed using the statistical package of social science (SPSS) version (20). Descriptive statistics were applied (e. g mean, standard deviation, frequency and percentage). Pearson's correlation coefficient was applied between quantitative variables. A significant level value was considered when $\mathrm{p}<0.05$. The smaller the p-value obtained, the more significant is the result $(*)$, less than 0.001 was considered highly significant $(* *)$. The $\mathrm{P}$ - value is the probability of error of the conclusion.

\section{Results:}

Table (1): Distribution of Study Subjects Regarding their Socio demographic Characteristics (n=40).

\begin{tabular}{|l|c|c|}
\hline \multicolumn{2}{|c|}{ Socio Demographic Variables } & \multicolumn{2}{c|}{ Study $(\mathbf{n = 4 0})$} \\
\cline { 2 - 4 } & No. & $\%$ \\
\hline Age / years & 3 & 7.5 \\
\hline$\bullet \quad 20-<26$ & 10 & 25 \\
\hline$\bullet \quad 26-<30$ & 18 & 45 \\
\hline$\bullet \quad 30-<35$ & 9 & 22.5 \\
\hline$\bullet \quad 35->35$ & \multicolumn{3}{|c|}{$\mathbf{3 2 . 9 5} \pm \mathbf{3 . 6 5}$} \\
\hline Mean \pm SD & \\
\hline Gender
\end{tabular}




\begin{tabular}{|l|c|c|}
\multirow{2}{*}{ Socio Demographic Variables } & \multicolumn{2}{c|}{ Study (n=40) } \\
\cline { 2 - 3 } & No. & $\mathbf{\%}$ \\
\hline Male & 8 & 20 \\
\hline Female & 32 & 80 \\
\hline Educational status & 10 & 25 \\
\hline Bachelor & 12 & 30 \\
\hline Technical Institute & 18 & 45 \\
\hline Diploma & 4 & 10 \\
\hline Occupation & 36 & 90 \\
\hline Head nurse & 17 & 42.5 \\
\hline Bed side nurse & 13 & 32.5 \\
\hline Working Department & 10 & 25 \\
\hline Oncology Surgical Dep. & \multicolumn{2}{|c|}{} \\
\hline Inpatient Chemotherapy & 8 & 20 \\
\hline General Surgical Dep. & 10 & 25 \\
\hline Years of experience & 22 & 55 \\
\hline$<5$ years & \multicolumn{2}{|l}{} \\
\hline 5-10years &
\end{tabular}

Table (1) Reveals that; more than one third of study sample (age was between $30>-35$ years and their mean age \pm SD was $32.95 \pm 3.65$, their educational level was Diploma in nursing $(45 \%)$ and working in Oncology Surgical department). The highest percentage of study sample $(80 \%)$ was females. Also, as regard to their occupation results shows that more than two thirds working as a bed side nurse. Finally, more than half of them $(55 \%)$ had $>10$ years of experience.

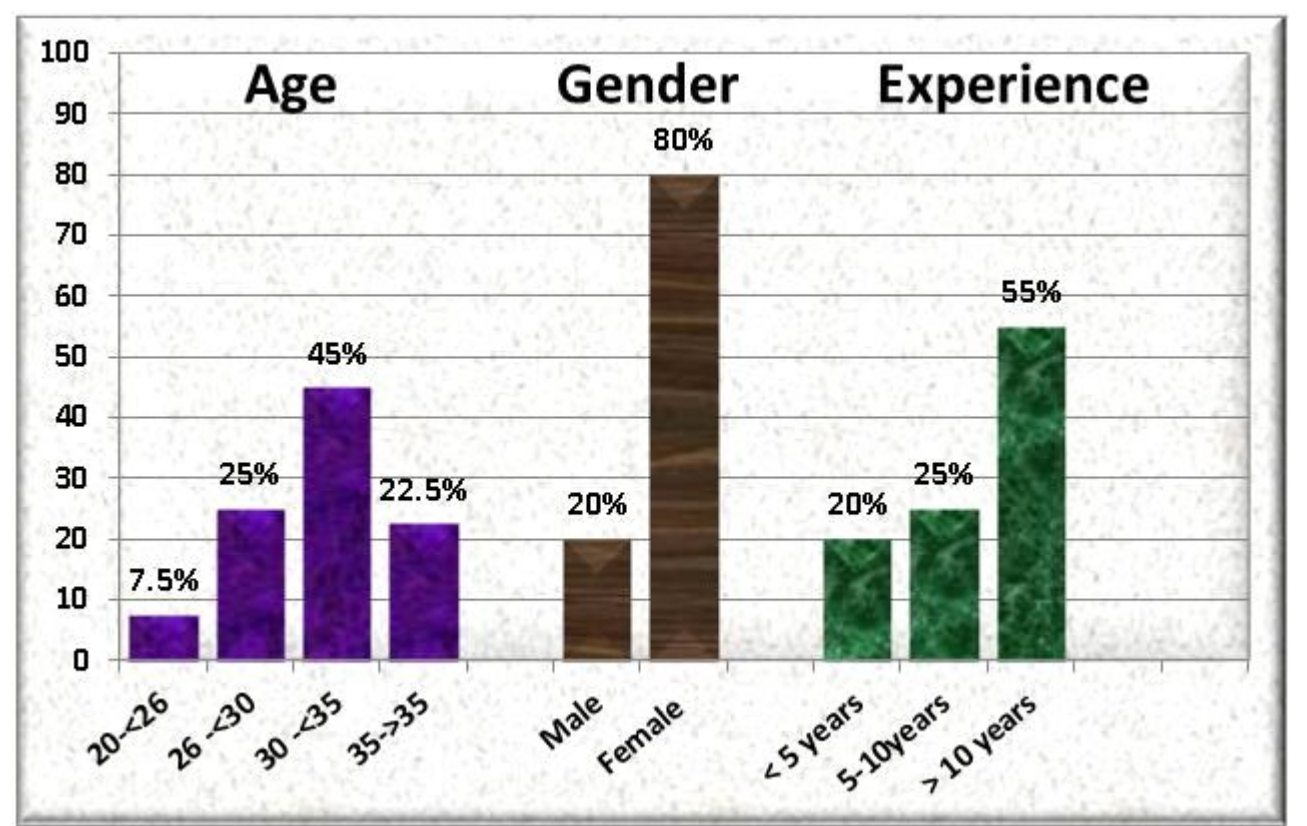

Figure (1): Distribution of Study Subjects Regarding to their Age, Gender \& Years of Experience (n=40)

Figure (1): Reflected that highest percentage (45\%) were belongs to $30-<35$ year of age \& least percentage $(7.5 \%)$ were in $20-<26$ years and their mean age \pm SD was $32.95 \pm 3.65$. Regarding to gender the highest percentage from them constituted $(80 \%)$ were females. Regarding to Years of experience, most of studied sample experiences was more than ten years constituted (55\%), on opposite side the least percentage of them was less than five years constituted $(20 \%)$.

Table (2): Distribution of Nurses knowledge Level regarding colostomy care educational program $(n=40)$

\begin{tabular}{|l|c|c|c|c|c|c|}
\hline \multirow{2}{*}{ Level of knowledge } & \multicolumn{2}{|c|}{ Pretest } & \multicolumn{2}{c|}{ Posttest } & \multicolumn{2}{c|}{ After 3 m. } \\
\cline { 2 - 7 } & No. & $\%$ & No. & $\%$ & No. & $\%$ \\
\hline Low Knowledge & 34 & 85 & 0 & 0 & 0 & 0 \\
\hline Moderate Knowledge & 5 & 12.5 & 29 & 72.5 & 6 & 15 \\
\hline High Knowledge & 1 & 2.5 & 11 & 27.5 & 34 & 85 \\
\hline Fisher (P - Value) & \multicolumn{3}{|c|}{$168.8\left(0.001^{* *}\right)$} & \\
\hline
\end{tabular}

\section{* Statistical significant $(\mathrm{P} \leq \mathbf{0 . 0 5}) \quad * *$ highly Statistical significant $(\mathrm{P} \leq \mathbf{0 . 0 1})$}

Table (2) Shows that, the majority of study group had low level of knowledge pre implementing colostomy care educational program, and more than two thirds of study group constituting had moderate knowledge level post-test, however the most of study group after education program had high knowledge with highly statistically significant differences $\left(\mathrm{p}=0.001^{* *}\right)$. 


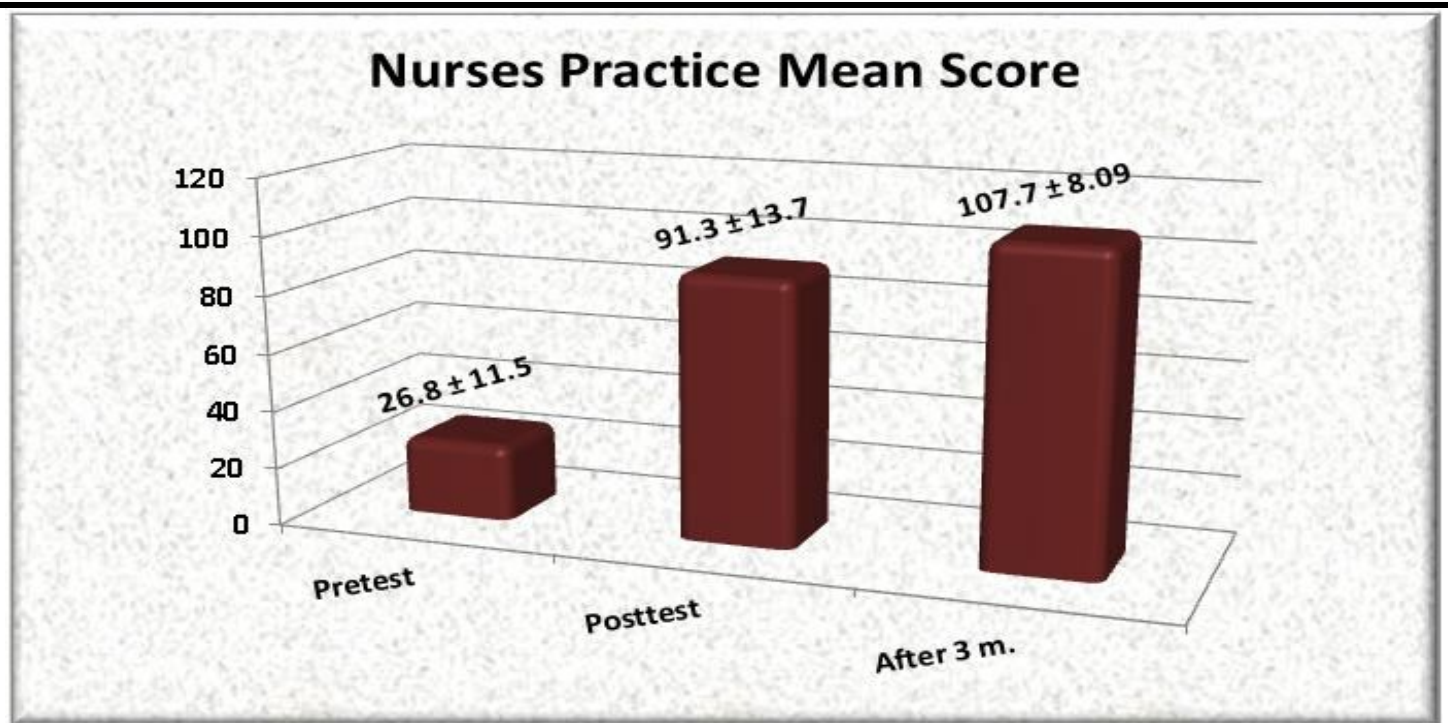

Figure (2): Nurses Practice Mean Score regarding colostomy care educational program $(n=40)$.

Fig (3): Reflected that Mean \pm SD in pre-test was (26.8 \pm 11.5$) \& i n$ posttest was (91.3 \pm 13.7$)$ and after 3 months was (107.7 \pm 8.09 ) and there was a highly statistical significant respectively .

Table (3): Distribution of Nurses Practice Level Regarding Colostomy care Educational Program $(n=40)$

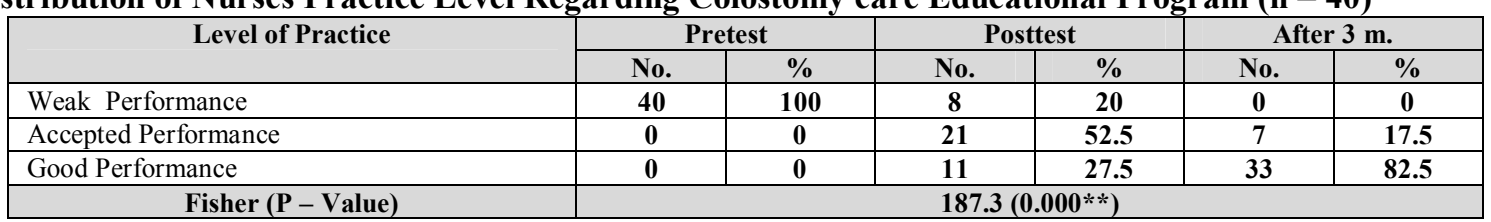

* Statistical significant $(\mathrm{P} \leq \mathbf{0 . 0 5}) \quad * *$ highly Statistical significant $(\mathrm{P} \leq 0.01)$

Table (3): Shows that, all of studied sample in pretest had weak performance level regarding colostomy care, while in posttest more than half of them had accepted performance, and after 3 months the majority had a good performance. There were statistical significant among pre, post, and after 3 months of implementing colostomy care educational program with p-value $(0.000 * *)$.

Table (4): Correlation between Nurse's Total Knowledge Scores and Total Practice Scores Regarding Colostomy Care educational program $(n=40)$.

\begin{tabular}{|c|c|c|c|c|c|c|}
\hline & \multicolumn{6}{|c|}{ Total knowledge Scores } \\
\hline & \multicolumn{2}{|c|}{ Pretest } & \multicolumn{2}{|c|}{ Posttest } & \multicolumn{2}{|c|}{ After 3 months } \\
\hline & $\mathbf{r}$ & $\mathbf{p}$ & $\mathbf{r}$ & $\mathbf{p}$ & $\mathbf{r}$ & $\mathbf{p}$ \\
\hline Total practice Scores & 0.105 & 0.519 & 0.364 & 0.021* & 0.304 & $0.047^{*}$ \\
\hline
\end{tabular}

\section{* Statistical significant $(\mathbf{P} \leq \mathbf{0 . 0 5})$}

Table (4): shows that, there were a positive correlation between total knowledge and total practice scores regarding colostomy care educational program $(n=40)$ where in posttest ( $\mathbf{r}$ value $=\mathbf{0 . 3 6 4} \& \mathbf{p}=\mathbf{0 . 0 2 1})$ more than $(\mathbf{r}$ value) in pre-test and after 3 months this reflected that there was a statistical significant in posttest and after 3 months.

Table (5): Correlation between selected Socio-demographic Characteristics (Age, Educational status and Years of experience) and Nurses Level of Practice of Implementing colostomy care educational program $(n=40)$

\begin{tabular}{|c|c|c|c|c|c|c|}
\hline \multirow[t]{3}{*}{ Socio Demographic Variables } & \multicolumn{6}{|c|}{ Level of Practice } \\
\hline & \multicolumn{2}{|c|}{ Pre } & \multicolumn{2}{|c|}{ post Immediately } & \multicolumn{2}{|c|}{ After 3 months } \\
\hline & $\mathbf{r}$ & p & $\mathbf{r}$ & p & $\mathbf{r}$ & $\mathbf{P}$ \\
\hline Age & 0.003 & 0.841 & 0.041 & 0.801 & 0.148 & 0.361 \\
\hline Educational status & 0.330 & 0.038* & 0.192 & 0.235 & 0.079 & 0.627 \\
\hline Years of experience & 0.142 & 0.382 & 0.137 & 0.398 & 0.080 & 0.0625 \\
\hline
\end{tabular}

Table (5) Shows that, there were no statistically significant correlation between the selected Socio-demographic Characteristics (Age \& Educational status\& Years of experience) of studied sample and their level of practice Pre\& post Immediately \&After 3 months colostomy care educational program, except with educational status, there was a significant correlation with the level of practice pre- educational program with p-value (0.038).

Table (6): Correlation between selected Socio-demographic Characteristics (Age, Educational status and Years of experience) and Nurses Level of Knowledge of Implementing colostomy care educational program (n=40)

\begin{tabular}{|c|c|c|c|c|c|c|}
\hline \multirow[t]{3}{*}{ Socio Demographic Variables } & \multicolumn{6}{|c|}{ Level of Knowledge } \\
\hline & \multicolumn{2}{|c|}{ Pre } & \multicolumn{2}{|c|}{ post Immediately } & \multicolumn{2}{|c|}{ After 3 months } \\
\hline & $\mathbf{r}$ & $\mathbf{P}$ & $\mathbf{r}$ & p & $\mathbf{r}$ & $\mathbf{P}$ \\
\hline Age & 0.145 & 0.290 & 0.023 & 0.889 & 0.028 & 0.865 \\
\hline Educational status & 0.212 & 0.190 & 0.303 & 0.058 & 0.149 & 0.360 \\
\hline Years of experience & 0.253 & 0.115 & 0.053 & 0.746 & 0.044 & 0.788 \\
\hline
\end{tabular}


Table (6) Shows that, there were no statistically significant correlation between the selected Socio-demographic Characteristics (Age \& Educational status\& Years of experience) of studied sample and their level of knowledge Pre\& post Immediately \&After 3 months colostomy care educational program.

\section{Discussion}

The world's third most common cause of cancer death is colorectal cancer (American Cancer Society .2017). Intestinal ostomy is a procedure to treat a variety of conditions such as acute diverticulitis, rectal cancer, trauma or bowel disease (Lewis, 2014).

The nursing function for patients with colostomy changing from a bed side nurse to a therapist or to enter stoma or a nurse with expertise in stoma care. Patients have the most significant and central function in health education to assist and persuade patients in self-care. They consider health educators in virtually every health care community to improve and promote patient health awareness in taking charge and getting acquainted with their condition (Walker, 2016).

In the next part, the discussion will concentrate on the main results:

Section I: will be dedicated to socio-demographic characteristic of studied groups regarding to colostomy care.

The present study showed that the majority of studied group's age ranged from thirty to below thirty five years with the mean age $\pm \mathrm{SD}$ was $(32.95 \pm \mathbf{3 . 6 5})$; this may be due to the desire of Mania Oncology center\& Mania university hospital roles in old years and to provide high-quality health care services, through employing new graduates of the faculty of nursing or nursing technical institute in additional to diploma nursing This result in our study may be due to increase the number of diploma nurses than qualified nurses due to old system of nursing teaching

The results of the current study were accepted (Arun Kadam, et al., 2014), which reported that the majority of samples studied age ranged between 30 and 34 years. Further confirmation was given for in (Mohamed, et al., 2017) by the study, which stated that over half of the studied sample age was between 29 and 34 years.

Conclusions also confirm the findings of the research by (Gem mill, et al. 2015) who reported that most of the sample age study ranged from 20 to 30 years.

Findings of the current study showed that more than two thirds of the total studied samples were females. This result may be explained by the fact that nursing is a universal feminine profession especially in our society culture. Furthermore, the findings confirms that the bulk of the sample analyzed (93.3 \%) were female (Betty Lebona et al. 2016).

Concerning to educational level; the present studied demonstrated that, more than one third of the studied sample were diploma in nursing, more than a quarter of the studied sample were technical institute and about a quarter of the studied sample were Bachelor of science in nursing( BSc). This may be explained by a little number of faculty's graduates had employed in the university hospital and other work in schools or ministry of health hospitals. Also the result supported finding by (Hashem \& Abusaad, 2016) More than half of nurses were diploma in nursing .But this result dis agree with (Betty Lebona, et al., 2016) Who stated that the majority of sample group studied BSc .

Concerning to years of experience current study found that more than half of studied sample experienced more than ten years; this finding was in the same line with study by
(Ahmed, 2016) who stated that more than one third of study samples of nurses their experienced more than ten years.

Concerning to occupation the present studied findings showed that more than three quarter of nurses working as bed side, and a small number of them working as a head nurse, this result supported by (Geleta, 2017) who report that the majority of nurses working as bed side nurse $(80 \%)$ working as bed side, $(20 \%)$ working as a supervisors , This finding is also similar to (Subih \& Neil, 2016) In their Jordanian report, that ostomy care is a responsibility of the bedside nurses who act pre- and postoperatively as nurses for stoma care.

Section II: is concerned with the assessment of nurse's knowledge level regarding colostomy care.

The current study results found that more than two third of the studied sample in pre educational program hadn't knowledge about colostomy care such as (Definition of colostomy ,causes, indication, return to work after colostomy).In the current study was found difference between pre-test and post immediately and after three month .

The current research findings showed that over half the samples analyzed had a correct response to the definition of colostomy, causes of colostomy, colostomy indication, etc. These observations are similar (Pandey \& Dhungana, 2017) that two third of the sample responded correctly and also, supported results by (Carlson, et al., 2017).

However, in the current study more than half of the studied sample had a moderate knowledge about colostomy care in immediate posttest and after 3 months of educational program implementation had a good knowledge about colostomy care.

This result is in line with one study (Pearson \& Helistrom, 2016), which stated that the post-educational program has more than half of the study sample had a moderate information, while after three months they had good and high information on colostomy care.

Also nursing workers with fewer than three years of experience. As the nurse does not know all facets of colostomy treatment, they have even had some work experience. Like previous research, a lower level of awareness among nurses with several years of work experience has proved to be due to an insufficient education status (Pancorbo, et al. 2017), and the current study has shown that nurses with a long working experience $(<10$ years) have little knowledge of colostomy care $(61,7 \%)$ because of lack of education in which about half of them have diploma in nursing.

This result agree with (Nabeel et al., 2013) conducted a study on Nursing care standards of colostomy care. The results showed that all nurses (100\%) had inadequate knowledge of the requirements for colostomy care in pre-testing while they know the standards for knowledge regarding-colostomy care at satisfactory level in immediately post and after 3 months.

Furthermore, a study on developments in skills and procedures in the care of patients with intestinal Stoma (Hashem \& Abusaad, 2016) support this result. The findings revealed that most nurses surveyed had no knowledge of the intestinal stoma in pre-test while, they all had a good 
understanding of intestinal stoma care in immediately post and after three months of education program implementation.

The current study also dis agree with (Betty Lebona, et al., 2016) who found that a high percentage of participants $(75.9 \%)$ were knowledgeable about colostomy care, also dis agree with the study done in Albanian revealed that $74 \%$ of the respondents were knowledgeable towards colostomy care in pre -test (Duruk \& Ucar, 2018).

\section{Section III: Evaluation of studied group's practice} about colostomy care.

With regard to overall colostomy nursing practices, the results in the current study have explained that the level of colostomy care practices by nurses has been effective over immediate post-patients and after 3 months of the educational program implementation. These results were confirmed by (Richboarg, etal., 2016), who reported that stoma care nurses with expert ostomy care and training can enhance patient outcomes in their study in Jordan.

This result was also confirmed by (Golik, et al., 2018) that continuous learning is one of the roles of nursing employees and the specificity of stoma nursing requires additional skills and expertise. The clarification shows that the clinical practice of stoma treatment requires skills to be updated and sufficient information to deal particularly with the patient and their families.

Section IV: As regards the relationship between selected socio-demographic variable of the studied nurses and their total knowledge:

The current study found that no statistical correlation between knowledge and selected socio-demographic variable, that is agreed with (Betty Lebona, 2016) who stated that no association between the demographic variables such as age, gender, educational qualification, with level of knowledge regarding colostomy care.

These results were followed by (Golik et al. 2018\&Swierzewski 2015), which reported that nurses who provide advancing treatment for Stoma patients should have a bachelor's degree in nursing and practice, so that they are able to advise, instruct and collaborate with doctors in stoma care from both patients and staff in other units.

But disagreement (Hashem\& Abusaad, et al., 2016) was found that there was a significant relationship between the education and years of experience of the studied nurses and their total knowledge regarding stoma care in patient before educational program implementation.

Also, this study clarified that two thirds of nursing supervisors who had nursing bachelor had average level of knowledge than the bedside nurses who had nursing diploma ,before program implementation while, more than half of bedside nurses had good knowledge after program implementation.

Section V: Regarding the relation between the total knowledge and the total practices of the studied nurses:

The current study clarified that, there was a statistically significant difference between nurses' knowledge and their practices regarding care of colostomy immediate post the educational program implementation and after 3 months This agreement (Doughty, 2017) says the interdependent relationship between nursing education and practice encourages and represents the advancement of others and that improvements of each other have an impact. In addition, the present study showed that after three months, the majority of nurses with good knowledge had competent practice, while over half had poor knowledge and incompetent colostomy practices before the introduction of the program.

This finding proves that, the nursing educational program intervention had a positive impact in the knowledge and practice scores of colostomy care and knowledge in the studied nurses after intervention of the educational program,

But the outcome disagrees (Nabeel, et al., 2013). Who said that the awareness of stoma care and experience with respect to the standards of colostomy for nursing care was weak, optimistic $(\mathrm{r}=0.15, \mathrm{p}=.3)$. This meant that the art of colostomy was not affected by experience. This is due to the possible awareness of colostomy, but due to the inexperience, lack of formal training, which can impact the practice rates, the nurse cannot provide treatment.

\section{Conclusion}

Based on the results of the present study it can be concluded that: After providing the education for studied nurses had a good level of knowledge and practice related to colostomy care.

\section{Recommendations}

(1) Greater attention had to be paid to nurses' performance during colostomy care.

(2) Educational needs should be assessed for staff and newly employed nurses working in Oncology Center \& Minia University Hospital.

(3) Training program should be arranged for nurses about colostomy care procedures and receive regular, periodic courses to update nurse's knowledge, based on evidence guidelines about colostomy care procedures.

\section{Acknowledgment}

The researchers would like to acknowledge the contribution of all participants who kindly agreed to take part in the study. They generously gave their time and attention to conduct this study. This study would have been impossible without their generosity.

\section{References}

(1) Ahmed, R. A. (2016). Developing Postoperative care standards for patients who had drainage of chronic subdural hematoma. submitted for partial fulfillment of Master Degree in Medical and surgical Nursing Faculty of Nursing, Assiut University.

(2) American Cancer Society. Survival Rates for Colorectal Cancer, by Stage. The American Cancer Society Available from: 2017. https://www.cancer.org/cancer/colon-rectalcancer/ detectiondiagnosis-staging/survival-rates.html.

(3) Arnold M, Sierra MS, Laversanne M, Soerjomataram I, Jemal A, Bray $\mathrm{F}$ et al. Global patterns and trends in colorectal cancer incidence and mortality. Gut. Journal. 2016; 31:0912.

(4) Arun Kadam, Mahadeo B. Shinde. (2014). Effectiveness of Structured Education on Caregivers Knowledge and Attitude Regarding Colostomy Care. International Journal of Science and Research. 122-136.

(5) Bryan S, Dukes, S. The Enhanced Recovery Programmed for Ostomy Patients: an Audit. Br J Nurse. 2017; 19(13):831-834.

(6) Carlson E., Gylin M., Nilsson, L., Swenson, K., Alverslid, I.and Persson E. (2018). Positive and negative aspects of colostomy irrigation: a patient and WOC nurse perspective. http://www.merriam-webster.com/dictionary/health. accessed at 21/4 2018.)

(7) Chindaprasirt, J., Limpawattana, P., Pakkaratho, P., Wirasorn, K., Sookprasert, A., Kongbunkiat, K., \& Sawanyawisuth, K. (2017). 
Burdens among caregivers of older adults with advanced cancer and risk factors. Asian Pac J Cancer Prev, 15(4), 1643-1648.

(8) Doughty, D. Integrating Advanced Practice and WOC Nursing EEducation. J Wound Ostomy Continence Nurs. 2017; 27:65-6.

(9) Duruk, N., \& Uçar, H. (2018). Staff nurses' knowledge and perceived responsibilities for delivering care to patients with intestinal ostomies: a cross-sectional study. Journal of Wound Ostomy \& Continence Nursing, 40(6), 618-622.

(10) Favoriti P, Carbone G, Greco M, Pirozzi F, Pirozzi RE, Corcione F et al Worldwide burden of colorectal cancer: A review. Updates in Surgery. 2016; 68(1):7-11.

(11) Ferlay J, Soerjomataram I, Dikshit R, Eser S, Mathers C, Rebelo M, Bray F. Cancer incidence and mortality worldwide: Sources, methods and major patterns in GLOBOCAN 2012. International Journal of Cancer, 2015; 136(5):359-386

(12) G Betty Lebona G, Elizabeth Jasmine S,Kanaka Lakshmi R, Dr. Indira S. Assess the knowledge regarding colostomy care among staff nurses and nursing students in $\mathrm{NMCH}$, Nellore. International Journal of Applied Research 2016; 2(5): 306-310.

(13) Geleta, T. (2017). Assessment of Knowledge and Associated Factors Regarding Colostomy Care among Staff Nurses Working in Surgical, ICU and Oncology Units at Selected Public Hospitals, Addis Ababa, Ethiopia, 2017 (Doctoral dissertation, Addis Ababa University).

(14) Gemmill, R., Kravits, K., Ortiz, M., Anderson, C., Lai, L., \& Grant, M. (2015). What do surgical oncology staff nurses know about colorectal cancer ostomy care?. The Journal of Continuing Education in Nursing, 42(2), 81-88.

(15) Golik, M., Kurek, M., Poteralska, A., Bieniek, E., Marynka, A., Pabich, G., Liebert, A., Klopocka, M. and Rydzewska G. Working group guidelines on the nursing roles in caring for patients with Crohn's disease and ulcerative colitis in Poland. Prz Gastroenterol. 2018; 9(4): 179-193.

(16) Hashem, S. F., \& Abusaad, F. E. S.(2016) Improving Nurses' Knowledge and Practices Regarding the Care of Children with Intestinal Stomas.

(17) Huang, C. W., Su, W. C., Chang, T. K., Ma, C. J., Yin, T. C., Tsai, H. L., ... \& Wang, J. Y. (2020). Impact of Previous Abdominal Surgery on Robotic-assisted Rectal Surgery in Patients With Rectal Cancer Undergoing Preoperative Chemoradiotherapy: A Propensity Score Matching Study.

(18) Lewis, Heitkemper Driksen , O’Brien Bucher. Medical Surgical Nursing, Assessment and management of clinical problems.7th ed: South Asian adaptation. 2014.
(19) Loughlin, P., Denost, Q., \& Rullier, E. (2018). Intersphincteric Resection: Perineal or Abdominal Dissection First?. In Current Common Dilemmas in Colorectal Surgery (pp. 341-353). Springer, Cham.

(20) Mohamed, Sabah S., G. M. Salem, and Hayam Ahmed Mohamed. "Effect of selfcare management program on self-efficacy among patients with colostomy." Am J Nurs Res 5.5 (2017): 191-9.

(21) Nabeel M. Bhzeh DNSea. Colostomy: Developing Nursing Care Standards for Patient with Colostomy. Med J Cairo University 2013, 81(2).

(22) Nazike Duruk HU. Staff Nurses' Knowledge and Perceived Responsibilities for Delivering Care to Patients With Intestinal Ostomies. 2017.

(23) Pancorbo $\square$ Hidalgo, P. L., García $\square$ Fernández, F. P., López $\square$ Medina, I. M., \& López- Ortega, J. (2017). Pressure ulcer care in Spain: nurses' knowledge and clinical practice. Journal of Advanced Nursing, 58(4), 327-338.

(24) Pandey, R.A., \& Dhungana, S. G. (2017). Knowledge and practice of stoma care among ostomates at b.p.koirala memorial cancer hospital, Journal of Nobel Medical College, 4(1), Issue 7, pp 36: 45.

(25) Pearson, E. and Helistrom, A.L. Experiences of Swedish men and women 6 to 12 weeks after ostomy surgery. Journal of Wound Ostomy and Continence Nurses, 2016; 29: 103-8.

(26) Potter, P. A., Perry, A. G., Stockert, P., \& Hall, A. (2016). Fundamentals of Nursing-E-Book. Elsevier Health Sciences; (9th edition), Chapter (47), (p.1167).

(27) Rafiemanesh H, Pakzad R, Abedi M, Kor Y, Moludi J, Towhidi F, Salehiniya $\mathrm{H}$ et al Colorectal cancer in Iran: Epidemiology and morphology trends. EXCLI Journal. 2016; 15:738-744.

(28) Richboarg, L., Thorpe, J.M. and Rapp, C.G. Difficulties experienced by the ostomate after hospital discharge. J Wound Ostomy Continence Nws. 2017; 34(1): 70-79.

(29) Sheikh A., Joel A., Johnson A. and Vimalach and ran D. (2013): Outcome of colorectal cancer resection in octogenarians. South African Journal of Surgery, 51(2), 68-72.

(30) Subih, M.M. and Neill, J.M. Ostomy educational program for nurses in Jordan. Wound Clinic Business. September, 29, 2016.

(31) Swierzewski, S. Gastrointestinal surgery, colostomy post-operative care and complications. NON Code standard for trust worthy health information, September, 2015.

(32) Walker C. (2016). Effects of the Use of a Heart Failure Diary on Self- Care and Quality of Life. Master's Thesis. UNF Digital Commons. University of North Florida.; 65: 1-55 